Ferdinand Opll et Martin Scheutz (dir.), Die

Osmanen vor Wien. Die Meldeman-Rundansicht von 1529/30. Sensation, Propaganda und Stadtbild

\title{
Axelle Chassagnette
}

\section{OpenEdition}

Édition électronique

URL : https://journals.openedition.org/ifha/11320

DOI : 10.4000/ifha. 11320

ISSN : 2198-8943

Éditeur

IFRA - Institut franco-allemand (sciences historiques et sociales)

Référence électronique

Axelle Chassagnette, «Ferdinand Opll et Martin Scheutz (dir.), Die Osmanen vor Wien. Die MeldemanRundansicht von 1529/30. Sensation, Propaganda und Stadtbild », Revue de l'IFHA [En ligne], Date de recension, mis en ligne le 12 mai 2021, consulté le 14 mai 2021. URL : http://journals.openedition.org/ ifha/11320 ; DOI : https://doi.org/10.4000/ifha.11320

Ce document a été généré automatiquement le 14 mai 2021.

(C)IFHA 


\title{
Ferdinand Opll et Martin Scheutz (dir.), Die Osmanen vor Wien. Die Meldeman-Rundansicht von 1529/30. Sensation, Propaganda und Stadtbild
}

\author{
Axelle Chassagnette
}

Cet ouvrage collectif est la publication des actes d'un colloque tenu à Vienne en mars 2019, et tout entier consacré à l'étude d'une œuvre gravée, la vue circulaire de la ville de Vienne lors du siège par les Ottomans en 1529. Cette vue (parfois également désignée comme plan) a été imprimée en avril 1530 à Nuremberg par Niclas Meldeman à partir de six bois gravés. Il s'agit, pour l'époque, d'une gravure d'assez grande taille $(81,2$ x 85,6 cm), qui comprend de nombreuses indications textuelles (en caractères typographiques) insérées dans l'image. La publication par Meldeman a bénéficié d'un privilège d'impression octroyé par le conseil urbain de Nuremberg, qui témoigne du soutien politique que la ville - pourtant déjà acquise à la Réforme - témoignait aux Habsbourg dans sa lutte contre les Ottomans, démontrant ainsi son appartenance légitime à un christianisme uni contre les hérétiques. L'œuvre n'est conservée qu'à quelques exemplaires. Le plus connu (et celui auquel il est en général fait référence dans les différents articles) faisait partie des collections royales de Dresde et a été acquis en 1927 par le Musée de la ville de Vienne. Il présente la particularité d'être enluminé : cette mise en couleur date sans doute du XVIe siècle. Une autre édition (vraisemblablement la seconde), qui porte un autre titre et témoigne peut-être d'une diffusion commerciale plus large, est conservée dans un exemplaire complet à la Bibliothèque nationale de France. On est, par ailleurs, bien renseigné sur le contexte de production de la vue gravée, situation plutôt rare pour ce type de document.

Meldeman, éditeur et graveur de l'œuvre, précise ainsi que son travail s'appuie sur un dessin réalisé en 1529 depuis la tour de la cathédrale de Vienne (Saint-Étienne), par un peintre « célèbre » et anonyme, mais sur lequel des hypothèses d'identification sont avancées. 
L'ouvrage comprend dix-huit articles répartis en une partie introductive, une partie conclusive (qui s'intéresse notamment à la mémoire politique du siège de Vienne de 1529 au XIXe siècle), et quatre sections consacrées respectivement à l'histoire de la production et de la transmission de l'exemplaire du Musée de Vienne, au contexte local (notamment politique, mais aussi scientifique) d'élaboration de l'œuvre au moment du siège de Vienne, au contexte viennois du même événement, et à l'analyse de la représentation de thèmes particuliers dans la vue circulaire. L'ensemble, rédigé en allemand à l'exception du chapitre conclusif (en anglais), est complété par des résumés en anglais de tous les articles, par une bibliographie conséquente et plurilingue, et par un index des noms et des lieux. Le livre comporte aussi trois reproductions de qualité des deux éditions connues (en couleurs et sans enluminure pour la première) et qui, une fois dépliées, atteignent presque la taille des originaux.

L'ampleur de l'ouvrage ne permet pas de rendre compte ici dans le détail de tous les articles, mais l'ensemble fournit une somme érudite et passionnante, qui est aussi un instrument de travail et de référence pour toute personne qui s'intéresserait au document étudié, et plus largement à la représentation graphique d'événements militaires ou politiques dans la première modernité. La concentration de la majorité des articles sur un unique objet conduit bien sûr à des redites, mais celles-ci sont d'ordre factuel et n'empêchent pas le déploiement d'analyses et d'hypothèses différenciées sur le document, contribuant à la richesse du volume. Certaines contributions, moins nombreuses, ne portent pas directement sur le plan circulaire mais exposent différents aspects du contexte politique ou scientifique (par exemple l'état de la production cartographique à Nuremberg ou à Vienne au début du XVIe siècle, ou la perception du siège de 1529 dans l'historiographie ottomane). Au travers de ces articles, le plan urbain de la Vienne assiégée apparaît comme un document polymorphe, qui relève à la fois de la tradition des vues urbaines, très importante à la Renaissance, de la feuille d'actualité et d'information, et du document de propagande politique. Il est, à ce titre, plus riche qu'un simple canard ou occasionnel. Associant savoir géographique et historique, il propose une représentation très plausible de Vienne, sans être parfaitement conforme à la réalité topographique et toponymique de la cité. Dans ce décor qui permet l'identification des lieux, Meldeman insère des scènes figurant de nombreux événements du siège, condensant ainsi le récit historique dans un document unique et construisant un média qui informe effectivement le public, mais qui est aussi un instrument de commémoration et de célébration des Habsbourg et d'une Europe chrétienne face à la menace ottomane. Comme le souligne Peter Barber dans l'article conclusif, une somme aussi riche et fouillée invite à la comparaison avec des documents comparables de la première modernité, mais aussi avec d'autres formes de publicité données en Europe à des événements d'ampleur analogue. 
INDEX

Thèmes : Histoire des États et des pouvoirs, Histoire de l'art, Histoire des sciences, Histoire des villes et des régions, Sources

Index chronologique : Période moderne

\section{AUTEUR}

AXELLE CHASSAGNETTE

Université Lumière Lyon 2, LARHRA-UMR 5190 